\title{
Correlation of Coronary Artery Calcium and Invasive Coronary Angiographically in Patients with Atypical Angina Pectoris (CACICA - Trial)
}

\author{
Majed Elshenat, $\mathrm{MD}^{1}$, Mohammed Balosha ${ }^{2}$, Mohammed Habib, $\mathrm{MD}, \mathrm{PhD}^{\mathbf{1}^{*}}$ \\ ${ }^{1}$ Alshifa Hospital, Cardiology Department, Gaza, Palestine \\ ${ }^{2}$ Alshifa Hospital, Radiology Department, Gaza, Palestine \\ *Corresponding author: Mohammed Habib, Cardiology Department, AlShifa Hospital, Gaza, Palestine. \\ E-mail: cardiomohammad@yahoo.com \\ Received date: November 08, 2019; Accepted date: November 25, 2019; Published date: November 29, 2019 \\ Citation: Elshenat Majed., Balosha M., Habib M. (2019) Correlation of Coronary Artery Calcium and Invasive Coronary Angiographically in \\ Patients with Atypical Angina Pectoris (CACICA - Trial). J Clinical Cardiology and Cardiovascular Interventions, 2(3); DOI:10.31579/2641- \\ 0419/029
}

Copyright: (C) 2019 Mohammed Habib. This is an open access article distributed under the Creative Commons Attribution License, which permits unrestricted use, distribution, and reproduction in any medium, provided the original work is properly cited.

\begin{abstract}
OBJECTIVES

This study correlated the multi - detector computed tomography (MDCT) calcium scores with the results of coronary angiography in diabatic and/or hypertensive patients with atypical angina pectoris in order to assess its value to predict or exclude significant coronary artery disease (CAD).

Background:

Muti-detector computed tomography is a sensitive method to detect coronary calcium. However, it is unclear whether it may play a role as a filter before invasive procedures in patients with atypical angina pectoris.

Methods:

A total of 150 patients (116 men and 34 women) with diabetic and/or hypertension for at least 5 years and atypical angina pectoris from a single center were included in our study. Patients underwent calcium screening with MDCT and have calcium score more than 100 , then all patient underwent invasive coronary angiography.

Results:

The Mean age was $62 \pm 5.7$ and $77.3 \%$ were male, $78 \%$ of men and $88.2 \%$ of women revealed significant coronary stenoses $(>50 \%$ lumen narrowing of left main trunk stenosis and $>70 \%$ stenosis of any epicardial coronary artery). Significant correlation between calcium scoring and significant coronary artery stenosis was seen (P: 0001). A 70\% were DM, 90\% were hypertensive and 61.3\% were HTN and DM. The LAD artery was the most stenotic artery by $53.3 \%$ followed by RCA (37.3\%) and finally LCX (30.7\%). one significant coronary artery was $42 \%$ followed by two significant CAD (26.7\%), while $9.3 \%$ included three-vessel disease. The significant coronary artery diseases was increased with age ( P: 0003)

Conclusions:

Coronary calcium proved to have good diagnostic performance for significant coronary artery stenosis in patient with atypical angina pectoris.

Keywords: myocardial infarction; primary PCI; pharmacoinvasive strategy
\end{abstract}

\section{Introduction}

Coronary heart disease is the leading cause of mortality in the Palestine and worldwide. The current gold standard to evaluate coronary artery disease is invasive coronary angiography (ICA). In Gaza alone, between 2015 and 2018 about 5411 coronary angiography and percutaneous coronary intervention procedures rose by $48 \%$ over the last 4 years from a rate of 80 per 100,000 population in 2015 to 155 per 100,000 population in 2018. [1]

The significant coronary artery stenosis among patients underwent diagnostic coronary angiography were $54.3 \%$ of patients with stable ischemic heart disease, $66.7 \%$ in patients with unstable angina pectoris and $92.7 \%$ in patient with ST elevation myocardial infarction. [1] There are two major concerns for the stable ischemic coronary artery disease patients: the first point: Coronary angiography is over-used and low-yield. And second point: Stress imaging has improved diagnostic accuracy and can avoid invasive cor angiography

Recent trials suggested the Coronary artery calcium (CAC) is highly specific feat coronary atherosclerosis, and many $\mathrm{CAD}$ patients are asymptomatic, and early det and treatment of CAD can reduce the incidence of acute coronary syndrome $[2,3]$ Studies have also shown that the coronary artery calcium score (CACS) is use refined risk stratification, particularly with high-risk patients and those with di mellitus [4,5]

Our aim of this study to confirm correlation between computed tomographic ca score with intermediate or high risk (Agatston score >100) and invasive co angiography (ICA) in patient with age more than 40 years and have diabetes hypertension since at least 5 years with atypical angina pectoris.(Figure 1 


\section{Patient $>40$ years old with Atypical Angina Pectoris}

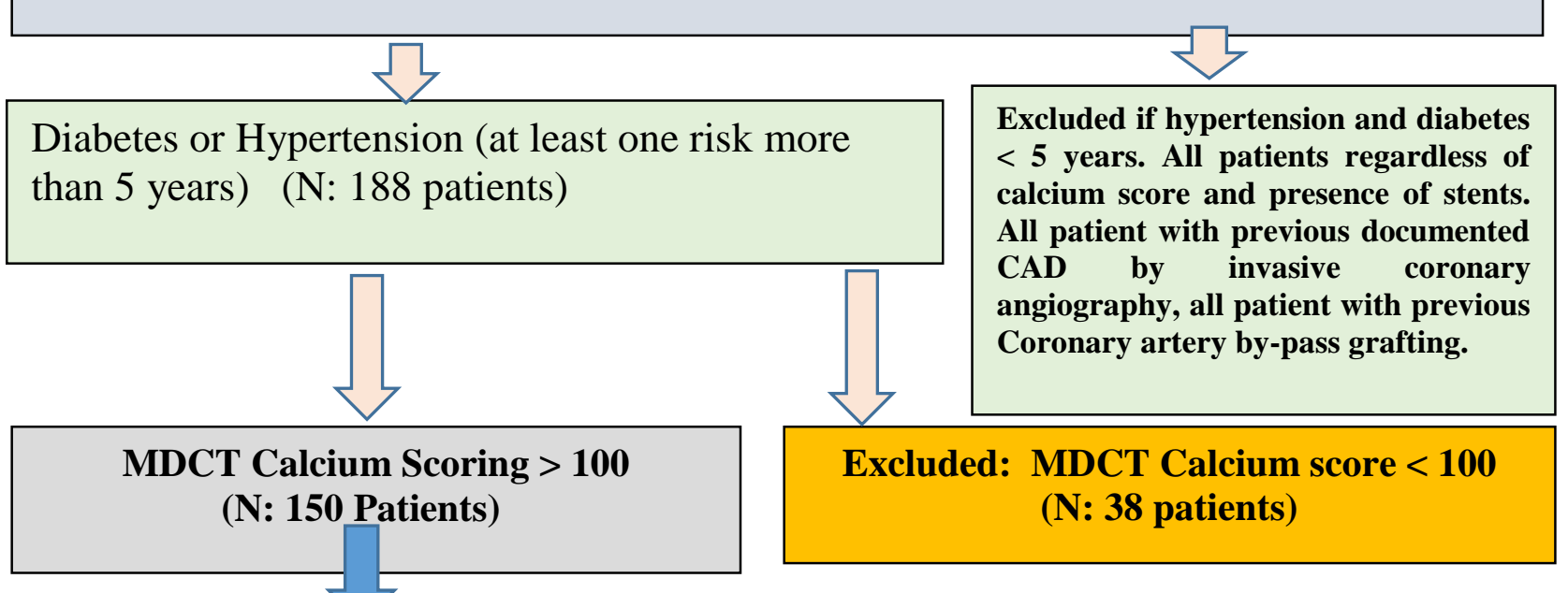

\section{Invasive Coronary Angiograph (N: 150 Patients)}

\section{Figure 1: Flow Chart of Patients in the Study}

\section{Methods}

\section{Study Design:}

In CACICA Gaza trial we conducted a cross-sectional study enrolling atypical angina pectoris patients with diabetes and/or hypertension for at least 5 years referred for cardiac evaluation of coronary artery disease before invasive coronary angiography. The inclusion period was from June 2018 to August 2019.

\section{Population of Patients:}

A total of 150 consecutive patients with coronary Calcium scoring > 100 according to agatston score and age older than 40 years patient with atypical angina pectoris and the presence of at least 1 of the following characteristics:

1. Diabetes treatment for more than 5 years

2. Hypertension treatment for more than 5 years

3. Diabetes and /or hypertension treatment for more than 5 years The exclusion criteria were age younger than 40 years, acute coronary syndrome patients, Diabetes and hypertension treatment for less than 5 years. All patients regardless of calcium score and presence of stents. All patient with previous documented CAD by invasive coronary angiography, All patient with previous Coronary artery by-pass grafting. Written informed consent was obtained from all patients.

\section{Definition of Atypical angina pectoris (6)}

Meets two of the following characteristics.

(i) Constricting discomfort in the front of the chest or in the neck, jaw, shoulder, or arm;

(ii) Precipitated by physical exertion;

(iii) Relieved by rest or nitrates within $5 \mathrm{~min}$.

\section{Calcium screening:}

The amount of calcium in the coronary arteries was assessed with a Multi Detector-Row CT (MDCT) scanner (IDT 124, Philips Medical Systems, and The Netherlands). Subjects were positioned within the gantry of the MDCT scanner in supine position. During a single breath hold, images of the heart, from the level of the tracheal bifurcation to below the base of the heart, were acquired using prospective ECG triggering at 50-80\% of the RR-interval, depending on the heart rate. Scan parameters were $16 \times 1.5 \mathrm{~mm}$ collimation, 205 $\mathrm{mm}$ field of view(FOV), $0.42 \mathrm{~s}$ rotation time, $0.28 \mathrm{~s}$ scan time per table position, $120 \mathrm{kVp}$ and $40-70 \mathrm{mAs}$ (patient weight <70 kg: 40 mAs; 70-90 kg: 55 mAs; >90 kg: 70 mAs). Scan duration was approximately $10 \mathrm{~s}$, depending on heart rate and patient size. After completing a the study, one scan reader manually selected the calcifications within one of the coronary arteries (left main, left anterior descending, left circumflex, right coronary artery, and PDA), three-dimensional connected components above the standard threshold of 130 Hounsfield Units (HU) were considered candidate calcifications. Each patient was assigned to one of five CVD risk categories based on Agatston score : low(0), fair(1-10), moderate(11$100)$,intermediate(101-400), high( $>400)$, if patient have intermediate or high agatston score coronary angiography is recommended.

Coronary angiography: The Judkin's technique was used with at least four views of the left coronary artery and two views of the right coronary artery. Analysis of the coronary angiograms was done by an independent, experienced observer who was unaware of the coronary calcium score. The decision to perform angiography was not influenced by the calcium score. Angiography was performed within 30 days after the MDCT. Significant stenosis was defined as $>50 \%$ lumen narrowing of left main trunk stenosis and > 70\% stenosis of any epicardial coronary artery.

\section{Statistical analysis:}

All data was analyzed by SPSS (version 23, IBM Corporation), For continuous variables that were not normally distributed $(\mathrm{p}<0.1$ [Shapiro-Wilks test]), the testing for differences was done using the nonparametric Wilcoxon test. For normally distributed variables, the Student $t$ test was employed. Categorical data were compared using 
the Fisher exact test or the Pearson chi-square test. The distributions of continuous variables were presented with their median and range (if not normally distributed), respectively, with their mean and SD. Categorical data were presented with absolute frequencies and percentages. A spearman correlation coefficient between CTCS and Coronary angiography, results of the statistical tests are presented with two-tailed $\mathrm{P}$ value of $<0.05$ were considered significant.

\section{RESULTS}

The total number of cases in this study was 150 with mean age $62 \pm 5.7$, the majority of participants $77.3 \%$ were male, $70 \%$ were DM, $90 \%$ were hypertensive and $61.3 \%$ were HTN and DM. Table 1

\begin{tabular}{|l|l|l|}
\hline & Frequency & Percent \% \\
\hline Sex (M) & 116 & 77.3 \\
\hline DM & 105 & 70.0 \\
\hline HTN & 135 & 90.0 \\
\hline DM+HTN & 92 & 61.3 \\
\hline
\end{tabular}

Table 1: Baseline characteristic of the study sample

Distribution of calcium deposit in coronary artery regards to agatston score

The quantification of calcium deposit in each coronary artery and total calcium score. The LAD artery got the largest quantity of calcium followed by RCA artery and finally LCX artery.

\begin{tabular}{|l|l|l|l|l|l|l|}
\hline \multicolumn{2}{|l|}{} & $\begin{array}{l}\text { CASC- } \\
\text { LMT }\end{array}$ & CASC-LAD & CASC-LCX & CASC-RCA & TOTAL CASC. \\
\hline \multirow{2}{*}{ Median } & 0 & 273.0000 & 121.5000 & 141.5000 & 476.0000 \\
\hline \multirow{3}{*}{ Percentiles } & 25 & 0 & 176.0000 & 71.5500 & 90.7500 & 386.0000 \\
\cline { 2 - 7 } & 75 & 0 & 362.0000 & 178.5000 & 264.2500 & 729.2500 \\
\hline
\end{tabular}

Table 2: The calcium score according to coronary arteries

Number and percent of diseased coronary artery regards to Coronary angiography

Most coronary angiography result included one significant coronary artery by $42 \%$ followed by two significant CAD (26.7\%), while $9.3 \%$ included three-vessel disease

\begin{tabular}{|l|l|l|l|}
\hline \multicolumn{2}{|c|}{} & Frequency & Percent \% \\
\hline \multirow{4}{*}{$\begin{array}{l}\text { No. of diseased coronary } \\
\text { artery by cath lab. }\end{array}$} & 0 & 33 & 22.0 \\
\cline { 2 - 4 } & 1.00 & 63 & 42.0 \\
\cline { 2 - 4 } & 2.00 & 40 & 26.7 \\
\cline { 2 - 4 } & 3.00 & 14 & 9.3 \\
\cline { 2 - 4 } & Total & 150 & 100.0 \\
\hline
\end{tabular}

Table 3: Number of significant coronary artery disease

Number and percent of significant stenosis in every coronary artery

Table 4.3 shows that the LAD artery was the most stenostic artery by $53.3 \%$ followed by RCA (37.3\%) and finally LCX (30.7\%).

\begin{tabular}{|l|l|l|}
\hline & Frequency & Percent \\
\hline Significant LAD stenosis & 80 & 53.3 \\
\hline Significant LCX stenosis & 46 & 30.7 \\
\hline Significant RCA stenosis & 56 & 37.3 \\
\hline Significant LMT stenosis & 2 & 1.3 \\
\hline
\end{tabular}


Table 4: Number and percent of significant stenosis in every artery in coronary

Comparison between coronary angiography and CT calcium scoring results: no difference between significant coronary artery stenosis in patient group with total Calcium score $>400$ and in patient group with calcium score <400. But the major group of significant number of coronary arteries was one vessel comparison between 2 and 3 significant coronary artery stenosis (P :0.018)

\begin{tabular}{|c|c|c|c|c|c|c|c|c|c|}
\hline & & & Total & $\begin{array}{l}\text { NO. } \\
\text { ARTE }\end{array}$ & $\begin{array}{r}\text { DISI } \\
\text { BY CA } \\
\end{array}$ & $\begin{array}{l}\text { D CC } \\
\text { AB. }\end{array}$ & DNARY & $\mathbf{X}$ & P-value \\
\hline & & & & (0 & 1 & 2 & 3 & $\mathrm{X} 2$ & P-value \\
\hline & 1 & $100-400$ & 39 & 9 & 23 & 7 & 0 & 10.064 & 0.018 \\
\hline calcium & & $\%$ of Total & $26.0 \%$ & $6.0 \%$ & $15.3 \%$ & $4.7 \%$ & $0.0 \%$ & $\begin{array}{l}\text { Total } \% \\
=79 \%\end{array}$ & of sig CAD \\
\hline & 2 & $>400$ & 111 & 24 & 40 & 33 & 14 & & \\
\hline & & $\%$ of Total & $74.0 \%$ & $16.0 \%$ & $26.7 \%$ & $22.0 \%$ & $9.3 \%$ & $\begin{array}{l}\text { Total } \% \\
=78 \%\end{array}$ & of sig CAD \\
\hline Total & & Count & 150 & 33 & 63 & 40 & 14 & & \\
\hline & & $\%$ of Total & $100 \%$ & $22.0 \%$ & $42.0 \%$ & $26.7 \%$ & $9.3 \%$ & & \\
\hline & & & & & Total $c$ & ig CAD & $78 \%$ & & \\
\hline
\end{tabular}

Table 5: Percent and number of compatible cath lab. And CT calcium scoring results

\section{Correlation between cath lab. and CT calcium scoring results}

A sperman correlation coefficient between CTCS and Coronary angiography. was done and revealed that there was a direct intermediate relationship between CTCS and Cath Lab except the LCX, where the relationship was weak direct relationship.

\begin{tabular}{|c|c|c|c|c|c|}
\hline & CASC-LMT & CASC-LAD & CASC-LCX & CASC-RCA & $\begin{array}{l}\text { TOTAL } \\
\text { CASC }\end{array}$ \\
\hline ANGIO-LMT & $\begin{array}{l}0.318 \\
\text { (P-value 0.386) }\end{array}$ & & & & \\
\hline ANGIO-LAD & & $\begin{array}{l}0.386 \\
\text { (P-value } 0.000)\end{array}$ & & & \\
\hline ANGIO-LCX & & & $\begin{array}{l}\text { 0.220 } \\
\text { (P-value0.007) }\end{array}$ & & \\
\hline ANGIO-RCA & & & & $\begin{array}{l}0.278 \\
\text { (P-value } 0.001)\end{array}$ & \\
\hline $\begin{array}{l}\text { TOTAL CTCS } \\
\text { AND CATH LAB }\end{array}$ & & & & & $\begin{array}{l}0.403 \\
\text { (P-value } \\
0.000)\end{array}$ \\
\hline
\end{tabular}

Table 6: Correlation between coronary angiography and CT calcium scoring results

Statistical test between No. of diseased coronary artery by Cath Lab. and patient characteristics (Sex, Age, HTN, DM and CTCS). 
No statistical significant differences at level (P- value < 0.05 ) between number of diseased coronary artery and sex, DM and HTN. While there was statistical significant differences at level $(\mathrm{P}$ - value $<0.05)$ between number of diseased coronary artery and age.

\begin{tabular}{|c|c|c|c|c|c|}
\hline & & $\begin{array}{l}\text { Total }=150 \\
\text { n }(\%)\end{array}$ & & Chi Square & \\
\hline & \multirow{2}{*}{$\begin{array}{l}\text { No. of } \\
\text { DISEASED } \\
\text { CA-Cath lab }\end{array}$} & \multirow{2}{*}{$\mathbf{N}$} & \multirow[t]{2}{*}{ Mean \pm SD } & $\begin{array}{l}\text { Statistical } \\
\text { Test }\end{array}$ & \multirow{2}{*}{ Sig } \\
\hline & & & & Anova & \\
\hline \multirow{5}{*}{ Age } & .00 & 33 & $60.94 \pm 4.55$ & \multirow{5}{*}{$\mathrm{F}=4.919$} & \multirow{5}{*}{0.003} \\
\hline & 1.00 & 63 & $60.83 \pm 6.24$ & & \\
\hline & 2.00 & 40 & $64.00 \pm 5.35$ & & \\
\hline & 3.00 & 14 & $65.43 \pm 4.09$ & & \\
\hline & Total & 150 & $62.12 \pm 5.7$ & & \\
\hline
\end{tabular}

Table 7: Statistical test results

\section{Discussion}

This study describes the value of MDCT calcium screening in patients with atypical angina pectoris with diabetes and/or hypertension for at least 5 years who were referred to our center with suspected CAD to be proven or excluded by coronary angiography.

The strength of this study is that all the patients were evaluated in a single center with the same technology; MDCT scans and angiography were performed within a 30 days of each other and were read by independent observers in a blinded manner.

There was no significant difference in coronary calcium between men and women however, the reliability of calcium testing in predicting significant stenosis was equally effective in men and women. Finally, the diagnostic benefit of calcium screening is maintained for all age groups.

The calcium score percentiles adjusted for age and gender are significantly higher in symptomatic versus asymptomatic patients with risk factors [7].

There is no agreement on what score cut point should be used in the clinical setting. Some studies solely used exclusion of any calcium [8 -12]. Other studies used a fixed score of 100 (13). In our study, significant coronary stenosis diagnosed by coronary angiography was found in $78 \%$ of the patient who had calcium score $>100$.

In CONFIRM trial, comparison between calcium scoring versus computed tomography coronary angiography. The patient with calcium score 100-400 and >50\% coronary artery stenosis were $35 \%$, and patients with calcium score $>400$ had $60 \%$ significant coronary artery stenosis. In our study comparison between calcium scoring versus invasive coronary angiography. The significant coronary artery stenosis was $78 \%$, In CONFIRM trial the diabetic patient was $18 \%$ but in our trial the diabetic patient was $90 \%$. In CONFIRM trial the hypertension was $59 \%$ and in our trial $70 \%$. This difference may be related multiple risk factors: First, High risk patient group in our trial compared with confirm trial. Second, patient group in our trial all patient was atypical angina pectoris, CONFIRM trial the patient group involved typical angina, atypical angina, noncardiac chest pain and dyspnea. Third, coronary artery stenosis confirmed by invasive coronary angiography but in CONFIRM trial computed tomography coronary angiography (14)

In the PROMISE Study, about $78 \%$ was atypical angina pectoris, $65 \%$ hypertensive and $21 \%$ diabetic, the significant coronary artery stenosis was $36 \%$ in patient with calcium score $>400$ and $20 \%$ in patients with calcium score 100-400. [15] in our trial $100 \%$ of patient was atypical angina pectoris, and $90 \%$ was diabetic.

In our trial patient with diabetic and/or hypertensive for at least 5 years and Calcium scoring 100-400 need coronary angiography, also supports the sequential testing algorithm evaluated in the CRESCENT trial (Calcium Imaging and Selective CT Angiography in Comparison to Functional Testing for Suspected Coronary Artery Disease) a prospective randomized trial that used CAC as a first-line test, advancing to CTA when CAC scores were 1 to 400. [16]

Clinical implications. On the basis of our results, we see an indication for calcium screening in patients with atypical angina pectoris and had diabetic and/or hypertension for at least 5 years, especially if noninvasive tests are not feasible or inconclusive. Calcium screening with MDCT has the potential as a filter in atypical symptomatic patients to reduce the number of invasive procedures which do not lead to intervention.

\section{Potential Conflict of Interest}

No potential conflict of interest relevant to this article was reported.

\section{Study Association}

This article is part of the Cardiology Board thesis. Palestinian Cardiology Board -AL Shifa Hospital - Gaza - Palestine 


\section{References}

1. Mohammed Habib, MD, PhD, Mohammed Adwan, MD, Mohammed Radi, MD, Mohanad Qwaider, MD, Mahmoud Altayyan, MD. (2019) Incidence and Trends of Ischemic Heart Disease and Coronary Revascularization Procedures in Gaza: A Descriptive Retrospective Study. Saudi Journal of Medicine:361-365

2. Robinson, J. G. \& Gidding, S. S. (2014) Curing atherosclerosis should be the next major cardiovascular prevention goal. Journal of the American College of Cardiology63, 2779-2785,

3. Lee, K. Y. et al. CT Angiography Images of Coronary Artery Stenosis Provide a Better Prediction of Risk Than Traditional Risk Factors in Asymptomatic Individuals With Type 2 Diabetes: A Long-term Study of Clinical Outcomes. Diabetes care,

4. Raggi, P., Shaw, L. J., Berman, D. S. \& Callister, T. Q. Prognostic value of coronary artery calcium screening in subjects with and without diabetes. Journal of the American College of Cardiology 43, 1663-1669,

5. Shemesh, J., Motro, M., Morag-Koren, N., Konen, E. \& Grossman, E. Relation of coronary artery calcium to cardiovascular risk in patients with combined diabetes mellitus and systemic hypertension. The American journal of cardiology109, 844-850,

6. Juhani Knuuti. (2019) ESC Guidelines for the diagnosis and management of chronic coronary syndromes. European Heart Journal (2019) 00,1_71

7. Raggi P, Callister TQ, Cooil B (2000) Identification of patients atincreased risk of first unheralded acute myocardial infarction byelectron-beam computed tomography. Circulation, 101:850-855

8. Rumberger JA, Sheedy PF, Breen JF, Schwartz RS. (1997) Electron beam computed tomographic coronary calcium score cut points and severityof associated angiographic lumen stenosis. J Am Coll Cardiol, 29:1542- 8.9.

9. Rumberger JA, Sheedy PF III, Breen JF, Schwartz RS. (1995) Coronary calcium, as determined by electron beam computed tomography, andcoronary disease on arteriogram: effect of patient's sex on diagnosis. Circulation, 91:13637.10.

10. Breen JF, Sheedy PF, Schwartz RS, (1992) Coronary artery calcificationdetected with ultrafast CT as an indication of coronary artery disease. Radiology, 185:435-9.11.

11. Fallavollita JA, Brody AS, Bunnell IL, Kumar K, Canty JM Jr. (1994) Fast computed tomography detection of coronary calcification in the diagnosis of coronary artery disease: comparison with angiography inpatients, 50 years old. Circulation 89:285-90.12.

12. Budoff MJ, Georgiou D, Brody A (1996) Ultrafast computed tomography as a diagnostic modality in the detection of coronary artery disease: a multicenter study. Circulation, 93:898 -904.913.

13. Schmermund A, Baumgart D, Gorge G. (1998) Measuring the effect ofrisk factors on coronary atherosclerosis: coronary calcium score versus angiographic disease severity. J Am Coll Cardiol 31:1267-1273.

14. Detrano R, Hsiai T, Wang S (1996) Prognostic value of coronary calcification and angiographic stenoses in patients undergoing coronary angiography. J Am Coll Cardiol 27:285-290.

15. Todd C. Villines, MD (2011) Prevalence and Severity of Coronary Artery Disease and Adverse Events Among Symptomatic Patients With Coronary Artery Calcification Scores of Zero Undergoing Coronary Computed Tomography Angiography. results from the CONFIRM (Coronary CT Angiography Evaluation for Clinical Outcomes: An International Multicenter) registry (J Am Coll Cardiol 58:2533-2540.

16. Matthew J. Budoff, MD. (2017) Prognostic Value of Coronary Artery Calcium in the PROMISE Study (Prospective Multicenter Imaging Study for Evaluation of Chest Pain) Circulation. 136:1993-2005.

17. Lubbers M, Dedic A, Coenen A, Galema T, Akkerhuis J. et al. (2016) Calcium imaging and selective computed tomography angiography in comparison to functional testing for suspected coronary artery disease: the multicentre, randomized CRESCENT trial. Eur Heart J.37:1232-1243. 